\title{
Sensitive and Rapid Detection of Pathogens Using Luminescent CdSe/ZnS dendron-nanocrystals and a Porous Membrane Immunofilter
}

\author{
Yongcheng Liu ${ }^{*}$, Robert Brandon, and Michael Cate \\ NN-Labs LLC, P. O. Box 2168, Fayetteville, AR 72702 \\ Xiaogang Peng* \\ Department of Chemistry \& Biochemistry, University of Arkansas, Fayetteville, AR 72701 \\ Robert Stony and Michael Johnson \\ Department of Food Science, University of Arkansas, Fayetteville, AR 72703
}

\begin{abstract}
A biosensor system for detection of pathogens was developed by using $\mathrm{CdSe} / \mathrm{ZnS}$ core/shell dendronnanocrystals with high efficiency and stability as fluorescence labels and a flowing chamber with a micro-porous immunofilter. The antibody-immobilized immunofilter captured the targeted pathogens, E. coli O157:H7 as an example for bacteria and Hepatitis B being a model system for viruses. The $\mathrm{CdSe} / \mathrm{ZnS}$ core/shell dendron-nanocrystals were conjugated with the corresponding antibodies and then passed through the micro-porous membrane where they attached to the membrane-antigen-antibody. The efficient and stable photoluminescence (PL) of the CdSe/ZnS nanocrystals on the formed "sandwich" structure complexes (membrane-antigen-antibody conjugated with the nanocrystals) was used as the detection means. The effects of the pore size of the membranes, buffer $\mathrm{pH}$, and assay time on the detection of $E$. coli $\mathrm{O} 157: \mathrm{H} 7$ were investigated and optimized. The detectable level of this new system was as low as $2.3 \mathrm{CFU} / \mathrm{ml}$ for E. coli $\mathrm{O} 157: \mathrm{H} 7$ and $5 \mathrm{ng} / \mathrm{ml}$ for Hepatitis B surface $\mathrm{Ag}(H B s A g)$. The assay time was shortened to $30 \mathrm{~min}$ without any enrichment and incubation.
\end{abstract}

\section{Keywords}

$\mathrm{CdSe} / \mathrm{ZnS}$ nanocrystals; photoluminescence; HBsAg detection; E. coli O157:H7 detection; immunoassay; biosensor; rapid detection

\begin{abstract}
Fluorescence measurements are the most widely used readout modalities in the life sciences today, from research at academic institutions to high-throughput screening by pharmaceutical companies. Colloidal semiconductor nanocrystals, or quantum dots (QDs), have recently been explored as a new generation of fluorescent labels in the field of bio-medical science owing to their unique optical properties, i.e., a broad absorption spectrum and a narrow, symmetric emission peak [1]. However, most QDs are synthesized in organic solvents and coated with a monolayer of hydrophobic ligands. Consequently, they have to be converted to water-soluble/ biocompatible nanoparticles for biological applications, which should have functional groups for bioconjugation such that the optical properties of the resulting nanocrystals are not diminished.
\end{abstract}

*Corresponding authors: Yongcheng Liu, phone: 479-575-3055, fax: 479-575-5115, email: ycliu@nn-labs.com. Xiaogang Peng, phone: 479-575-4612, fax: 479-575-4049, email: xpeng@uark.edu. 
In the recent years, quite a few of strategies have been, and are still being, designed to make QDs water-soluble and biocompatible. A recent review provided a summary of them [2]. These strategies can be separated into two different approaches: surface-ligand exchange by hydrophilic ligands and coating of the QDs with additional layers of water-soluble molecules. In the former, the initial ligand molecules are replaced with bifunctional molecules, such as cysteines [3], thiol-containing molecules with a hydrophilic terminal group (such as mercapto alkanoic acids) [5-6], and more sophisticated ones such as oligomeric phosphines [7], peptides [8], and dendrons [9-11]. The common nature in all of these new ligands is that the outer surface of the nanocrystal-ligand complex is terminated with some hydrophilic groups, such as carboxyl, amine, PEG units, or alcoholic groups. In the second approach, the initial ligand molecules are not removed but interact with the hydrophobic part of amphiphilic molecules. The hydrophilic part of the amphiphilic molecules, which is exposed to the solvent, ensures the solubility and enables additional functionalization. This procedure has been successfully carried out with different amphiphilic molecules, leading to QDs encapsulated in phospholipid micelles [12-13], or covered by a shell of polymers [14-19].

Since biocompatible QDs for biological applications were first described $[4,20]$, they have been utilized in many biological assays. These include DNA sorting, immunoassays, fluorescence resonance energy transfer (FRET)-based sensing, bio-optical coding, cellular and "animal" imaging, etc, as described in recent literatures [2,21-26]. Current tightened security and health concerns worldwide have placed a large burden on the scientific community to rapidly develop numerous biodetection assays for rapid, robust, simple, and efficient detection of pathogens in various media, such as in the natural environment, food, and drinking water [27]. These assays and their reagents will need to be stable in various environments for long periods of time. The unique properties of QDs make them an ideal candidate for developing such biodetection assays. Demonstrations of this capability have recently started to appear in some publications. For example, biotinylated CdSe-ZnS QD conjugates could detect as little as $10 \mathrm{ng} / \mathrm{ml}$ staphylococcal enterotoxin type-B [28]; antibody conjugated QDs were used to detect single E. coli $\mathrm{O} 157$ bacterial cells [29-30]; antibody-conjugated QDs were demonstrated to simultaneously detect four toxins: cholera toxin, ricin, shiga-like toxin 1 , and staphylococcal enterotoxin B in single wells of a microtiter plate [31]; antibody conjugated QDs and magnetic separation were used to detect E. coli O157:H7 and Salmonella Typhimurium [32-33]; and antibody conjugated QDs could also detect Listeria monocytogenes cell surface proteins [34].

In this report, a new hydrophilic dendron ligand was designed and synthesized. It successfully converted CdSe/ZnS core-shell nanocrystals into water-soluble dendron-nanocrystals by ligand exchange. These dendron-nanocrystals retained the optical properties of the assynthesized nanocrystals, were stable in desired conditions for biomedical labeling, and were further verified to possess needed conjugation chemistry by conjugating different antibodies onto the dendron-nanocrystals.

With these bio-functionalized dendron-nanocrystals as the fluorescent labels, a new design of biosensor system was developed. Another key feature of this biosensor system was a polymer micro-porous membrane immobilized with antibodies as an immunofilter for capturing the targets, which allowed the rapid flow through of a large volume of a liquid sample. This flow design coupled with the bright luminescence of QDs enabled the rapid detection of pathogens. One example for two main categories of pathogens will be discussed here, E. coli O157:H7 for bacteria and Hepatitis $\mathrm{B}$ for viruses. Both of these example pathogens were detected at low concentrations, 2.3 CFU/ml for E. coli $\mathrm{O} 157: \mathrm{H} 7$ and $5 \mathrm{ng} / \mathrm{ml}$ for Hepatitis B surface $\mathrm{Ag}$ (HBsAg). 


\section{EXPERIMENTAL SECTION}

\section{Synthesis of Dendron Coated CdSe/ZnS Nanocrystals (Dendron-nanocrystals)}

$\mathrm{CdSe} / \mathrm{ZnS}$ core-shell dendron-nanocrystals were made by typical surface modification of $\mathrm{CdSe} / \mathrm{ZnS}$ core-shell nanocrystals with the dendron ligands [11]. The syntheses of the dendron ligands and $\mathrm{CdSe} / \mathrm{ZnS}$ core-shell nanocrystals are described in the supporting information section. Typically, $1.0 \mathrm{ml}$ of purified $\mathrm{CdSe} / \mathrm{ZnS}$ core-shell nanocrystals in chloroform solution (OD 1.0) and $1.0 \mathrm{ml}$ of G-3 dendron ligands in methanol solution $(10 \mathrm{mg} / \mathrm{ml})$ were added into an $8 \mathrm{ml}$ vial. After adjusting the $\mathrm{pH}$ to 12, the mixture was sonicated in a sonicator (Branson) for $4 \mathrm{~h}$. Then, ethyl acetate was added into the vial to precipitate the nanocrystal complexes and the heterogeneous solution was centrifuged. After the supernatant was decanted, the precipitates were washed with ethyl acetate three times. The solid was re-suspended in a mixture of methanol and chloroform. Afterwards, another $1.0 \mathrm{ml}$ of G-3 dendron ligands in methanol solution $(10 \mathrm{mg} / \mathrm{ml})$ was added into the above mixture and the mixture was sonicated in a sonicator for another $4 \mathrm{~h}$. The procedure for precipitation and purification was repeated with ethyl acetate. The purified dendron-nanocrystals could be dissolved in water and various aqueous media.

\section{Conjugation of Antibodies onto CdSe/ZnS Dendron-Nanocrystals}

Conjugation of antibodies onto $\mathrm{CdSe} / \mathrm{ZnS}$ core shell dendron-nanocrystals was achieved by using classic EDC coupling reactions of $\mathrm{COOH}$ groups onto the surfaces of the dendronnanocrystals and $\mathrm{NH}_{2}$ groups of the antibody. Typically, $0.1 \mathrm{ml}$ of CdSe $/ \mathrm{ZnS}$ core-shell dendron nanocrystals ( $\mathrm{OD}=1.08), 20 \mu \mathrm{l}$ of $30 \mathrm{mg} / \mathrm{ml} \mathrm{EDC}$ (1-ethyl-3-(3-dimethylaminopropyl) carbodiimide hydrochloride) and $20 \mu \mathrm{l}$ of $32 \mathrm{mg} / \mathrm{ml}$ sulfo-NHS (N-hydroxysulfosuccunimide) were added into a $1.5 \mathrm{ml}$ tube. After adjusting the $\mathrm{pH}$ to around 7.4 in PBS (phosphate buffer saline), $0.1 \mathrm{ml}$ of $1 \mathrm{mg} / \mathrm{ml}$ antibody (anti-Escherichia coli O157:H7 antibody purchased from KPL inc. Gaithersburg, MD, USA; anti-Hepatitis B surface Ag (HBsAg) provided by Fitzgerald Industries International, Inc., Concord, MA, USA) was added into the above tube and the mixture was shaken at $600 \mathrm{rpm}$ at room temperature for $1.5 \mathrm{~h}$. In order to block unreacted $\mathrm{COOH}$ groups on the surfaces of the $\mathrm{CdSe} / \mathrm{ZnS}$ core-shell dendron-nanocrystals, $10 \mu \mathrm{l}$ of ethylenediamine, another $60 \mu \mathrm{lof} 30 \mathrm{mg} / \mathrm{ml}$ EDC and another $60 \mu \mathrm{l}$ of $32 \mathrm{mg} / \mathrm{ml}$ sulfo-NHS were added into above $1.5 \mathrm{ml}$ tube, and the tube was shaken at $600 \mathrm{rpm}$ at room temperature for another $1.5 \mathrm{~h}$. The mixture was transferred into a 10k microfilter tube and centrifuged at 2,000 rpm. In order to remove all small molecules such as EDC, NHS and ethylenediamine, the mixture was washed for 3 times with PBS ( $\mathrm{pH}$ 7.4) solution. The purified antibody conjugated nanocrystals were ready to be used to detect the target pathogens.

\section{Construction of the Antibody Immobilized Membrane Immunofilter}

A micro-porous nylon membrane was chosen as the matrix for antibody immobilization to form the base of the immunofilter because of its mechanical strength and biocompatibility. The scheme of immobilization of antibodies onto the micro-porous nylon membrane is illustrated in Figure 1. Typically, a 10 micron nylon membrane (Sterlitech Corperation, Kent, WA) was immersed in dimethyl sulfate and shaken at $600 \mathrm{rpm}$ for $5 \mathrm{~min}$ at room temperature. Then the membrane was washed with chloroform and acetone, respectively. The functionalized membrane was immersed in $2 \mathrm{M} 6$-aminocaproic acid solution and shaken at $600 \mathrm{rpm}$ for $2 \mathrm{~h}$ at room temperature. After that, the membrane was washed with PBS (pH7.4) solution to remove the unreacted 6-aminocaproic acid on the surface of the membrane. Finally, the membrane was immersed in a solution containing $0.1 \mathrm{ml}$ of antibodies $(1 \mathrm{mg} / \mathrm{ml}), 20 \mu \mathrm{l}$ of EDC $(30 \mathrm{mg} / \mathrm{ml})$ and $20 \mu \mathrm{l}$ of sulfo-NHS $(32 \mathrm{mg} / \mathrm{ml})$ and shaken for $2 \mathrm{~h}$ at $600 \mathrm{rpm}$ at room temperature. The membrane was taken out and washed 3 times with PBS (pH7.4) solution. 


\section{Biosensor Design and Target Detection}

The biosensor design was based on the traditional immunoreaction between antibodies and antigens. In order to shorten detection time and achieve a lower detection limit, the biosensor utilized a micro-porous polymer membrane as a matrix for an immunofilter that provides a large surface area for antibody immobilization. The stream flowing from the bottom to the top of the immunofilter was expected to increase the chance for contact between the targets and the solid-phase immobilized antibodies. The smaller diameter of the membrane's pores was expected to dramatically increase the interactions between pathogens and antibodies and the opportunities of capturing individual pathogens by the immobilized antibodies. Therefore, this antibody immobilized membrane immunofiltration system could not only accelerate the diffusion-controlled rate of immunological reactions within the surface of the sensing element of the system, but also concentrate pathogens on the membrane by filtering a large volume of the sample out. What's more, the membrane immunofiltration was easy to automatically wash the surface for minimizing the nonspecific binding by the buffer flow in order that the whole process be made automatic. The biosensor system is schematically presented in Figure 2. In principle, the immobilized antibodies on the surface of the micro-porous polymer membrane in the immunofilter capture the target antigens and form immunocomplexes (antibody-antigen) on the surface of the membrane when the samples pass through the membrane. The formed immunocomplexes on the surface of the membrane continue to react with the dendronnanocrystal conjugated antibodies and form "sandwich" structure immunocomplexes (immobilized antibodies on surface of membrane - antigens from samples - dendronnanocrystal conjugated antibodies). The targets are indirectly detected by measuring the photoluminescence from the dendron-nanocrystals that are part of the immunocomplexes on the surface of the micro-porous membrane. The typical procedure for detection of E. coli O157: H7 is as follows: $1 \mathrm{ml}$ of the diluted $E$. coli $\mathrm{O} 157: \mathrm{H} 7$ culture was injected into the inlet of the immunofilter cartridge in which the antibody immobilized membrane was assembled. The membrane was washed by injecting PBS solution into the cartridge to remove unreacted $E$. coli $\mathrm{O} 157: \mathrm{H} 7$ on the surface of the membrane. Then, the nanocrystal labeled antibody solution was injected to form a sandwich structure immunocomplex (immobilized antibody - E. coli O157: H7 - nanocrystal labeled antibody). Finally, the above membrane was washed 3 times by injecting a PBS ( $\mathrm{pH}$ 7.4) solution and the photoluminescence was measured by a spectrofluorometer (Fluorolog-3, Horiba Jobin Yvon, Irvine, CA). The Hepatitis B surface Ag (HBsAg) detection was followed the same procedure.

\section{Microbial Tests}

The conventional microbial plating method was used for enumeration of bacterial cells. The $0.1 \mathrm{ml}$ diluted solutions of $E$. coli $\mathrm{O} 157: \mathrm{H} 7$, L. monocytogenes or $S$. typhimurium were plated on Sorbitol MacConkey Agar (Remel, Lexexa, KS), Oxford agar (Oxoid LTD, Basingstoke Hampshire, UK), or XLT4 agar (Remel, Lenexa, KS), respectively, and incubated at $37^{\circ} \mathrm{C}$ for $24 \mathrm{~h}$ for enumeration of the bacteria. The pure cultures of E. coli O157:H7 (ATCC 43888), Listeria monocytogenes (ATCC 13932) and Salmonella typhimurium (ATCC 14028) were grown in brain heart infusion (BHI) (Difco, Detroit, MI) broth at $37^{\circ} \mathrm{C}$ for $20-24 \mathrm{~h}$. The culture samples were serially diluted from 1 to $10^{-8}$ with $5.0 \times 10^{-2} \mathrm{M}$ phosphate buffer $(\mathrm{pH} 7.4)$ for use. The bacterial samples for the biosensor were killed by heating the culture to $100{ }^{\circ} \mathrm{C}$ for $15 \mathrm{~min}$.

\section{RESULTS AND DISCUSSION}

\section{Characterization of the CdSe/ZnS Dendron-Nanocrystals}

The synthesis of the CdSe/ZnS core-shell nanocrystals coated with dendron ligands (CdSe/ $\mathrm{ZnS}$ core-shell dendron-nanocrystals) followed a standard procedure reported previously for $\mathrm{CdSe} / \mathrm{CdS}$ core/shell dendron-nanocrystals (See Supporting Information). Characterization of 
these new dendron-nanocrystals was also performed following standard protocols. Because their optical properties and stability are critical issues for bio-medical applications as fluorescent labels, a brief discussion for these issues is provided below.

The new $\mathrm{CdSe} / \mathrm{ZnS}$ core-shell dendron-nanocrystals were completely dissolved in aqueous solutions and the solutions are very clear. The TEM picture (Figure 3) verifies that dendronnanocrystals are not aggregated, but are separately dispersed in the solution and have the same size as in toluene solution before ligand exchange.

The new CdSe/ZnS core-shell dendron-nanocrystals in aqueous solutions retained similar optical properties as the corresponding core/shell nanocrystals coated with the original akylamine ligands dissolved in toluene (Figure 4). The emission peak was shifted slightly to higher energy ( $6 \mathrm{~nm}$ shorter than that of the as-synthesized nanocrystal in toluene solution for the example in Figure 4). The quantum yield (36\%) of the CdSe/ZnS core-shell dendronnanocrystals in aqueous solutions retained $90 \%$ of the initial nanocrystals (40\% quantum yield) in toluene solution, in similarity with polymer coated nanocrystals $[16,19]$. In comparison to the $\mathrm{CdSe} / \mathrm{CdS}$ core/shell dendron-nanocrystals [9-11], the new CdSe/ZnS core-shell dendronnanocrystals were generally higher in quantum yield. This was likely due to the better confinement of the $\mathrm{ZnS}$ shell in comparison to the CdS shell. Under short wave (254 nm) UV irradiation, these $\mathrm{CdSe} / \mathrm{ZnS}$ core-shell dendron-nanocrystals (Figure 5, top plot) did not present significant photo-brightening as observed for CdSe/CdS dendron-nanocrystals [9-11]. Even after 30 days of photo-irradiation under ambient conditions, the PL brightness was only fluctuating with no significant decrease. However, the photo-irradiation process induced a slow but observable blue-shift of the UV-Vis absorption and PL spectra (Figure 5, bottom plot). After these 30 days of continuous photo-irradiation, the dendron-nanocrystals remained soluble in aqueous solution. The optical properties, characterized by their UV-Vis and PL spectra, of the $\mathrm{CdSe} / \mathrm{ZnS}$ core-shell dendron-nanocrystal aqueous solutions in a sealed vial remained the same over two years stored on the shelf under room light and ambient conditions. Judging by the PL quantum yield and solubility, $\mathrm{CdSe} / \mathrm{ZnS}$ core-shell dendron-nanocrystals were significantly more stable than $\mathrm{CdSe} / \mathrm{CdS}$ core-shell dendron-nanocrystals studied previously [9-11]

The CdSe/ZnS core-shell dendron-nanocrystals achieved good solubility in the common biological buffers such as PBS buffer solutions, acetic buffer solutions and Tris buffer solutions, and $2 \mathrm{M} \mathrm{NH}_{4} \mathrm{Ac}$ solution. In strong chemical conditions, such as in $1 \mathrm{M} \mathrm{HCl}$ or $3 \%$ $\mathrm{H}_{2} \mathrm{O}$ solution, the dendron-nanocrystals survived for about $5 \mathrm{~min}$.

\section{Bioconjugation of Antibodies onto the CdSe/ZnS Core-Shell Dendron-Nanocrystals}

The EDC coupling reaction between a carboxylic group and an amine group is the classic reaction for bioconjugation of biomolecules. Excess reagent and isourea formed as the byproduct of the cross-linking reaction are both water-soluble and may be easily removed by dialysis or filtration [35]. In this case, an improved EDC coupling reaction was approached by using EDC plus sulfo-NHS. The advantage of adding sulfo-NHS to the EDC reaction was to increase the stability of the active intermediate formed between EDC and CdSe/ZnS dendronnanocrystals, which ultimately reacted with the attacking amine from the antibodies. In general, EDC reacts with a carboxylate group to form an active ester leaving group. Unfortunately, this reactive complex is subject to rapid hydrolysis in aqueous solutions, having a rate constant measured in seconds. If the target amine does not find the active carboxylate before hydrolysis, the desired coupling cannot occur. This is especially a problem when the target molecule is low in concentration compared to water, as in the case of protein molecules. Forming a sulfoNHS ester intermediate from the reaction of the hydroxyl group on sulfo-NHS with the EDC active-ester complex extends the half-life of the activated carboxylate to hours. Since the 
concentration of added sulfo-NHS is usually much greater than the concentration of the target molecules, the reaction preferentially proceeds through the longer-lived intermediate.

In this work, the antibodies and the $\mathrm{CdSe} / \mathrm{ZnS}$ dendron-nanocrystals were large molecules and their concentrations were low, so the improved EDC coupling reaction could increase the yield of bioconjugation. In order to block unreacted carboxylic groups on the surface of the dendronnanocrystals, ethylenediamine was added to the above solution and continued to react with the unreacted carboxylic groups on the surface of the dendron-nanocrystals. The PL quantum yield of the $\mathrm{CdSe} / \mathrm{ZnS}$ dendron-nanocrystals after this conjugation process retained $70 \%$ of the initial $\mathrm{CdSe} / \mathrm{ZnS}$ dendron-nanocrystals, then recovered to the initial brightness (36\% of the quantum yield) of the initial $\mathrm{CdSe} / \mathrm{ZnS}$ dendron-nanocrystals gradually over a period of a couple of hours. After this initial recovering stage, the nanocrystal-antibody bioconjuagtes were found to be stable and their brightness remained the same after one-year of storage in a refrigerator at $4{ }^{\circ} \mathrm{C}$ in the PBS (pH 7.4) solution

\section{Design of the Biosensor System}

The biosensor system in this work was based on a flowing chamber with an immunofilter coupled with sensitive and robust dendron-nanocrystals as the detection indicator (Figure 2). In order to enhance the efficiency of the immunoreaction between antibodies and pathogens, shorten the detection time, and reduce the detection limit, a micro-porous polymer membrane was chosen as a matrix for the immunofilter. The membrane provided following features: a large surface area for antibody immobilization, proper-sized pores in the membrane for forcing the immunoreaction between antibodies and pathogens in a space that is small but sufficiently large enough for the flow of sample solution. In order to increase the contact chances of targets with the solid-phase immobilized antibody and the uniform stream, the sample stream was designed to flow from bottom to top of the immunofilter. The detection scheme of the bacteria was based on measuring the PL intensity of the QDs on the sandwich immunoplexes on the surface of the membrane (Figure 2). This design could also potentially be developed to be compatible with a fluorescence scanner. Two types of pathogens, E. coli $\mathrm{O} 157: \mathrm{H} 7$ as one example for bacteria and Hepatitis B representing a virus, were detected using the new biosensor system. Effects of different pore size of the membrane and the $\mathrm{pH}$ of the nanocrystalbioconjugate solution on the biosensor system performance were explored and discussed in the supporting information section.

\section{Detection of Pathogens}

The results shown in Figure 6 (inset) illustrate the typical photoluminescence spectra from one set of experiments with different concentrations of E. coli $\mathrm{O} 157: \mathrm{H} 7$ in the culture samples under the optimized conditions discussed above. The intensity of the PL spectra increased monotonically with the concentration of E. coli O157:H7. It should be pointed out that, the PL signal was slightly above zero for the controls, the brain heart infusion broth which was used to grow these pure cultures of E. coli O157:H7, Listeria monocytogenes and Salmonella typhimurium, or $1 \%$ BSA without any bacteria, indicating a low but visible level of nonspecific bonding on the immunofilter. However, even when the concentration of $E$. coli $\mathrm{O} 157: \mathrm{H} 7$ was as low as $2.3 \mathrm{CFU} / \mathrm{ml}$, the PL signal was substantially stronger than the control. The ratio of the signal from sample to the one from the control is more than 3 to 1 . If $2.3 \mathrm{CFU} / \mathrm{ml}$ is taken to be the detection limit of this technology, it is significantly lower than the published results of other existing technologies, such as $10^{2} \mathrm{CFU} / \mathrm{ml}$ reported by the first author and his coworkers [36-41] and $10^{3}-10^{4} \mathrm{CFU} / \mathrm{ml}$ by others [32-33]. Moreover, the dynamic range of the current technology is broad, from $10^{0}$ to $10^{7} \mathrm{CFU} / \mathrm{ml}$. The assay time was $30 \mathrm{~min}$ without prior enrichment and incubation of the sample. The low detection limit and broad working range could have resulted from two factors: the high capturing efficiency of bacteria with the microporous membrane and the bright and durable PL of the dendron-nanocrystals on the sandwich 
immunocomplexes. The high capturing efficiency was due to the large surface area of the micro-porous membrane for immobilizing antibodies, and the small diameters of the pores as well as the active flow stream from bottom to top of the immunofilter in the cartridge, which enabled sufficient contact between bacteria and the antibodies immobilized onto the pores of the membrane. These factors could result in enhancing the antigen-antibody encounter rate and capturing efficiency of pathogens during a short immunoreaction time. The large dynamic range was likely ascribed to the extremely large total surface area of the micro-porous membrane for efficiently capturing a large amount of bacteria when they were presented in the concentrated sample solutions. The specificity of the biosensor system was explored and discussed in the supporting information section. The other bacteria such as S. typhimurium, $L$. monocytogenes seems a little interferential on the detection of E. coli $\mathrm{O} 157: \mathrm{H} 7$ due to nonspecific binding.

The same biosensor design was used to detect another type of pathogens, a virus, HBsAg. The results shown in Figure 7 indicated that the same technology worked also very well for the virus detection. The detection limit was about $5 \mathrm{ng} / \mathrm{ml}$ for $H B s A g$ with $10 \mathrm{mg} / \mathrm{ml}$ BSA as a control.

\section{CONCLUSIONS}

A new $\mathrm{CdSe} / \mathrm{ZnS}$ dendron-nanocrystal synthesized by ligand exchange with a new G-3 dendron ligand and $\mathrm{CdSe} / \mathrm{ZnS}$ core/shell nanocrystals was stable and highly photoluminescent as a fluorescence label for antibodies. A technique for conjugation of antibodies onto the dendronnanocrystal was developed on basis of the EDC coupling reaction and the bioconjugates were sensitive to detection of their corresponding targets. A micro-porous nylon membrane was successfully functionalized as a matrix for antibody immobilization and a micro-porous immunofilter was successfully developed by immobilizing antibodies onto the functionalized micro-porous nylon membrane. A biosensor system based on a flowing chamber with the micro-porous immunofilter and the $\mathrm{CdSe} / \mathrm{ZnS}$ dendron-nanocrystals as fluorescence labels was developed. The performance of this biosensor system was examined for detection of two main classes of pathogens, bacteria and viruses. The detection limit of this new biosensor system was much lower (as low as $2.3 \mathrm{CFU} / \mathrm{ml}$ for E. coli O157:H7 and $5 \mathrm{ng} / \mathrm{ml}$ for $H B s A g$ ) than other published biosensor systems whose detection limits were $\sim 500$ for Bacillus globigii (Bg) by using membrane-based on-line optical analysis system [42], 10 ${ }^{3} \mathrm{CFU} / \mathrm{mL}$ for E. coli O157:H7 in $2 \mathrm{~h}$ by using immunomagnetic separation and a CCD-array $10^{4} \mathrm{CFU} / \mathrm{mL}$ for spectrometer [32], E. coli $\mathrm{O} 157 \mathrm{H} 7$ and Salmonella Typhimurium using quantum dots as fluorescence labels [33]. Obviously, the biosensor system was much sensitive than the published biosensor system. The assay time of the biosensor system was short, just $30 \mathrm{~min}$. This biosensor system could be extended to detect other pathogens or other targets. However, the specificity of the biosensor system still needs to be improved.

\section{Supplementary Material}

Refer to Web version on PubMed Central for supplementary material.

\section{Acknowledgements}

This research was supported in part through the NIH (1R43GM069065-01 and 5R43GM069065-02) and EPA (EPD-05-028).

\section{References}

1. Alivisatos AP. Science 1996;271:933-937. 
2. Michalet X, Pinaud FF, Bentolila LA, Tsay JM, Doose S, Li JJ, Sundaresan G, Wu AM, Gambhir SS, Weiss S. Science 2005;307:538-544. [PubMed: 15681376]

3. Sukhanova A, Venteo L, Devy J, Artemyev M, Oleinikov V, Pluot M, Nabiev I. Lab Invest 2002;82:1259-61. [PubMed: 12218088]

4. Chan WCW, Nie SM. Science 1998;281:2016-2018. [PubMed: 9748158]

5. Jiang W, Mardyani S, Fischer H, Chan WCW. Chem Mater 2006;18:872-878.

6. Boldt K, Bruns OT, Gaponik N, Eychmuller A. J Phys Chem B 2006;110:1959-1963. [PubMed: 16471768]

7. Kim S, Bawendi MG. J Am Chem Soc 2003;125:14652-14653. [PubMed: 14640609]

8. Pinaud F, King D, Moore HP, Weiss S. J Am Chem Soc 2004;126:6115-6123. [PubMed: 15137777]

9. Guo W, Li JJ, Wang YA, Peng X. Chem Mater 2003;15:3125-3133.

10. Guo W, Li JJ, Wang YA, Peng X. J Am Chem Soc 2003;125:3901-3907. [PubMed: 12656625]

11. Liu Y, Kim M, Wang Y, Wang Y, Peng X. Langmuir 2006;22:6341-6345. [PubMed: 16800696]

12. Dubertret B, Skourides P, Norris DJ, Noireaux V, Brivanlou AH, Libchaber A. Science 2002;298:1759-62. [PubMed: 12459582]

13. Geissbuehler I, Hovius R, Martinez KL, Adrian M, Thampi K, Ravindranathan T, Vogel H. Angew Chem, Int Ed 2005;44:1388-1392.

14. Moffit M, Vali H, Eisenberg A. Chem Mater 1998;10:1021-1028.

15. Wu X, Liu H, Liu J, Haley KN, Treadway JA, Larson JP, Ge N, Peale F, Bruchez MP. Nat Biotechnol 2003;21:41-6. [PubMed: 12459735]

16. Pellegrino T, Manna L, Kudera K, Liedl T, Koktysh D, Rogach AL, Keller S, Radler J, Natile G, Parak WP. Nano Lett 2004;4:704-7.

17. Gao X, Cui Y, Levenson RM, Chung LW, Nie S. Nat Biotechnol 2004;22:969-976. [PubMed: 15258594]

18. Kim SW, Kim S, Tracy JB, Jasanoff A, Bawendi MG. J Am Chem Soc 2005;127:4556-4557. [PubMed: 15796504]

19. Luccardini C, Tribet C, Vial F, Marchi-Artzner V, Dahan M. Langmuir 2006;22:2304-2310. [PubMed: 16489822]

20. Bruchez M Jr, Moronne M, Gin P, Weiss S, Alivisatos AP. Science 1998;281:2013-2016. [PubMed: 9748157]

21. Bagwe RP, Zhao X, Tan W. J Disper Sci Technol 2003;24:453-464.

22. Riegler J, Nann T. Anal Bioanal Chem 2004;379:913-919. [PubMed: 15278340]

23. Medintz IL, Uyeda HT, Goldman ER, Mattoussi H. Nat Mater 2005;4:435-446. [PubMed: 15928695]

24. Parak WJ, Pellegrino T, Plank C. Nanotechnology 2005;16:R9-R25.

25. Goldman ER, Medintz IL, Mattoussi H. Anal Bioanal Chem 2006;384:560-563. [PubMed: 16344927]

26. Smith AM, Dave S, Nie SM, True L, Gao XH. Expert Rev Mol Diagn 2006;6:231-244. [PubMed: 16512782]

27. Enserink M. Science 2001;294:1266-1267. [PubMed: 11701907]

28. Lingerfelt BM, Mattoussi H, Goldman ER, Mauro JM, Anderson GP. Anal Chem 2003;75:40434049. [PubMed: 14632116]

29. Zhao X, Hilliard LR, Mechery SJ, Wang Y, Bagwe RP, Jin S, Tan W. PNAS 2004;101:15027-15032. [PubMed: 15477593]

30. Hahn MA, Tabb JS, Krauss TD. Anal Chem 2005;77:4861-4869. [PubMed: 16053299]

31. Goldman ER, Clapp AR, Anderson GP, Uyeda HT, Mauro JM, Medintz IL, Mattoussi H. Anal Chem 2004;76:684-688. [PubMed: 14750863]

32. Su X, Li Y. Anal Chem 2004;76:4806-4810. [PubMed: 15307792]

33. Yang L, Li Y. Analyst 2006;131:394-401. [PubMed: 16496048]

34. Tully E, Hearty S, Leonard P, O’Kennedy R. Intern J Biolog Macromol 2006;39:127-134.

35. Hermanson, GT. Bioconjugate techniques. Academic Press Inc.; San Diego, CA: 1996.

36. Liu Y, Ye J, Li Y. J Rapid Method Auto Microbiol 2001;9:85-96.

37. Liu Y, Li Y. J Microbiol Methods 2002;5(3):369-377. [PubMed: 12223297] 
38. Ye J, Liu Y, Li Y. Trans ASAE 2002;45:473-478.

39. Liu Y, Ye J, Li Y. J Food Protection 2003;66(3):512-517.

40. Liu Y, Ye J, Li Y. J Rapid Method Auto Microbiol 2001;9:85-96.

41. Liu Y, Li Y. Anal Chem 2001;73:5180-5183. [PubMed: 11721916]

42. Floriano PN, Christodoulides N, Romanovicz D, Bernard B, Simmons GW, Cavell M, McDevitt JT. Biosensors and Bioelectronics 2005;20:2079-2088. [PubMed: 15741078] 


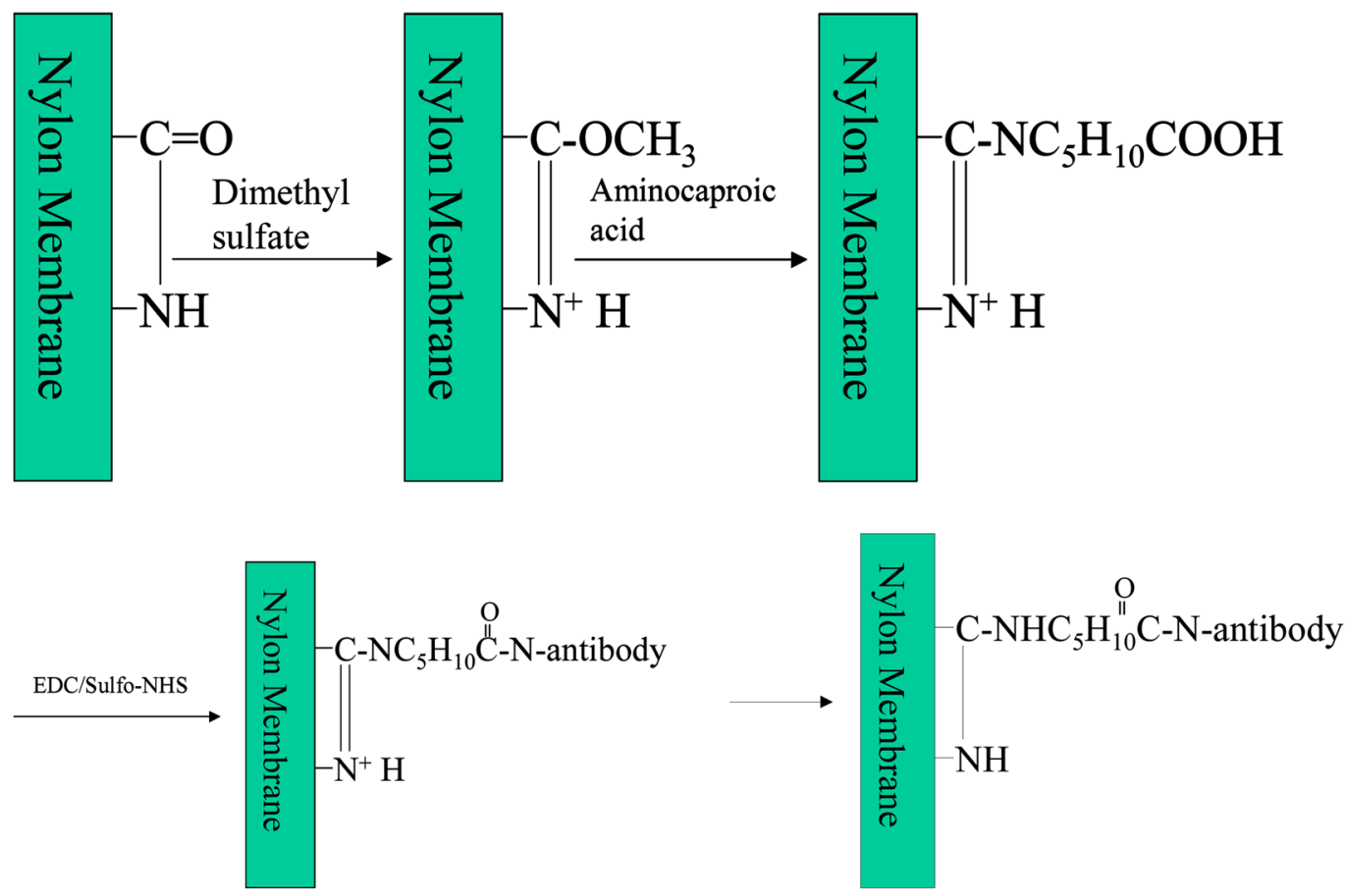

Figure 1.

The schematic representation of the immobilization of an antibody onto the micro-porous nylon membrane. 

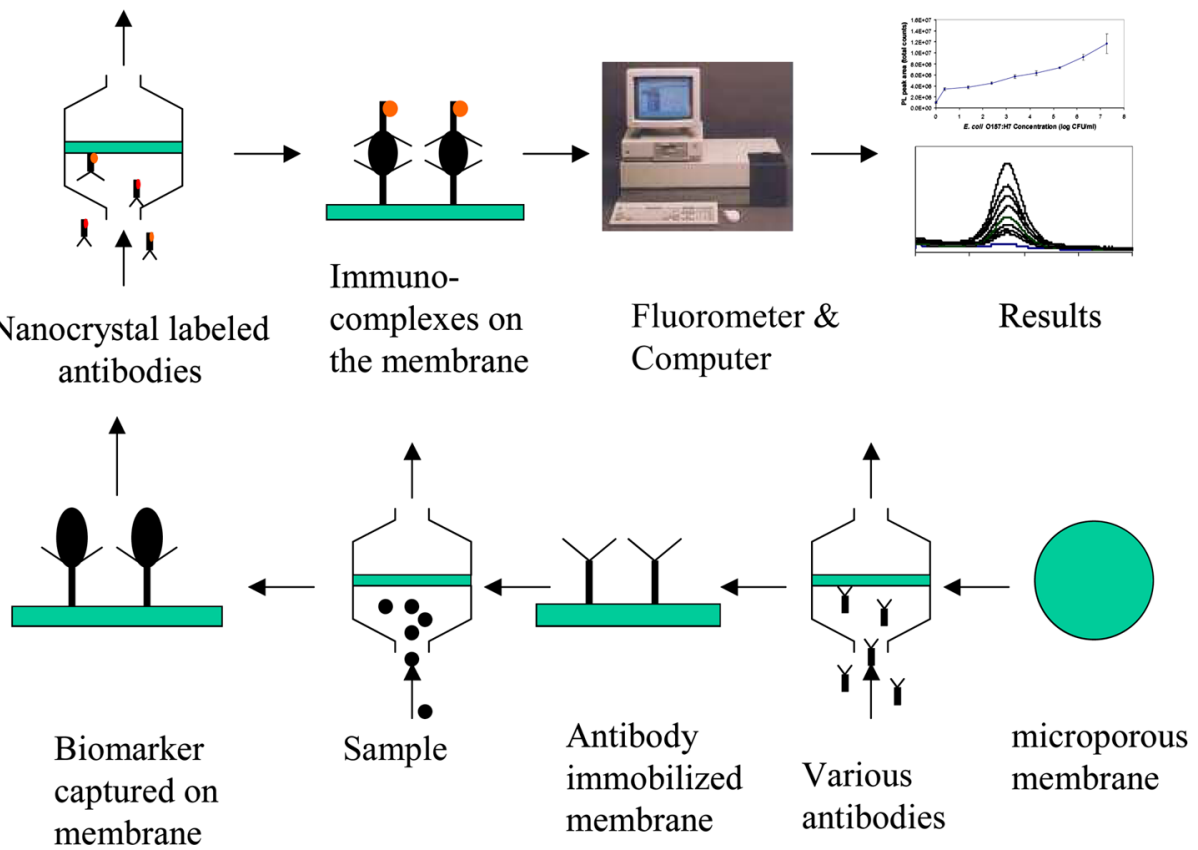

Figure 2.

The schematic representation of the biosensor process. 


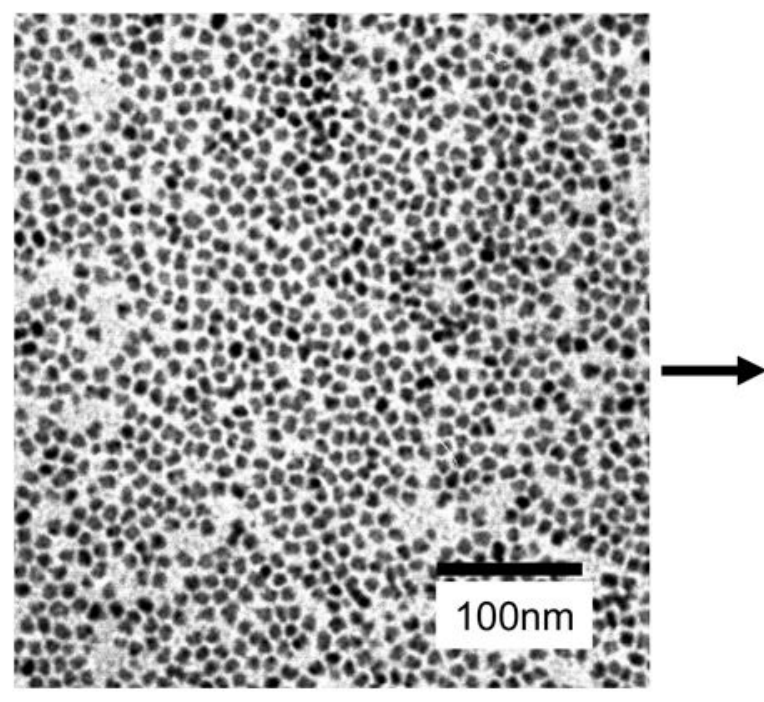

CdSe/ZnSe core-shell

nanocrystals in toluene

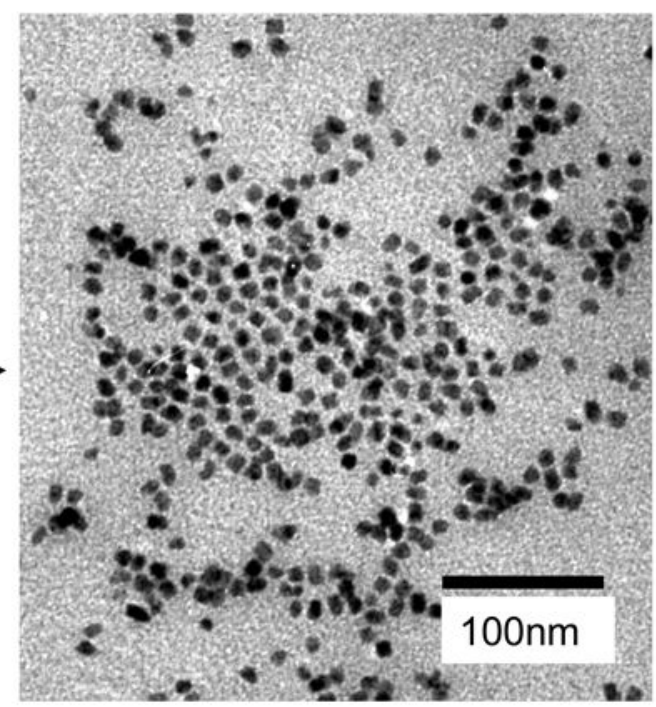

CdSe/ZnSe core-shell dendron nanocrystals in $\mathrm{H} 2 \mathrm{O}$

Figure 3.

The TEM picture of the CdSe/ZnS nanocrystals. 


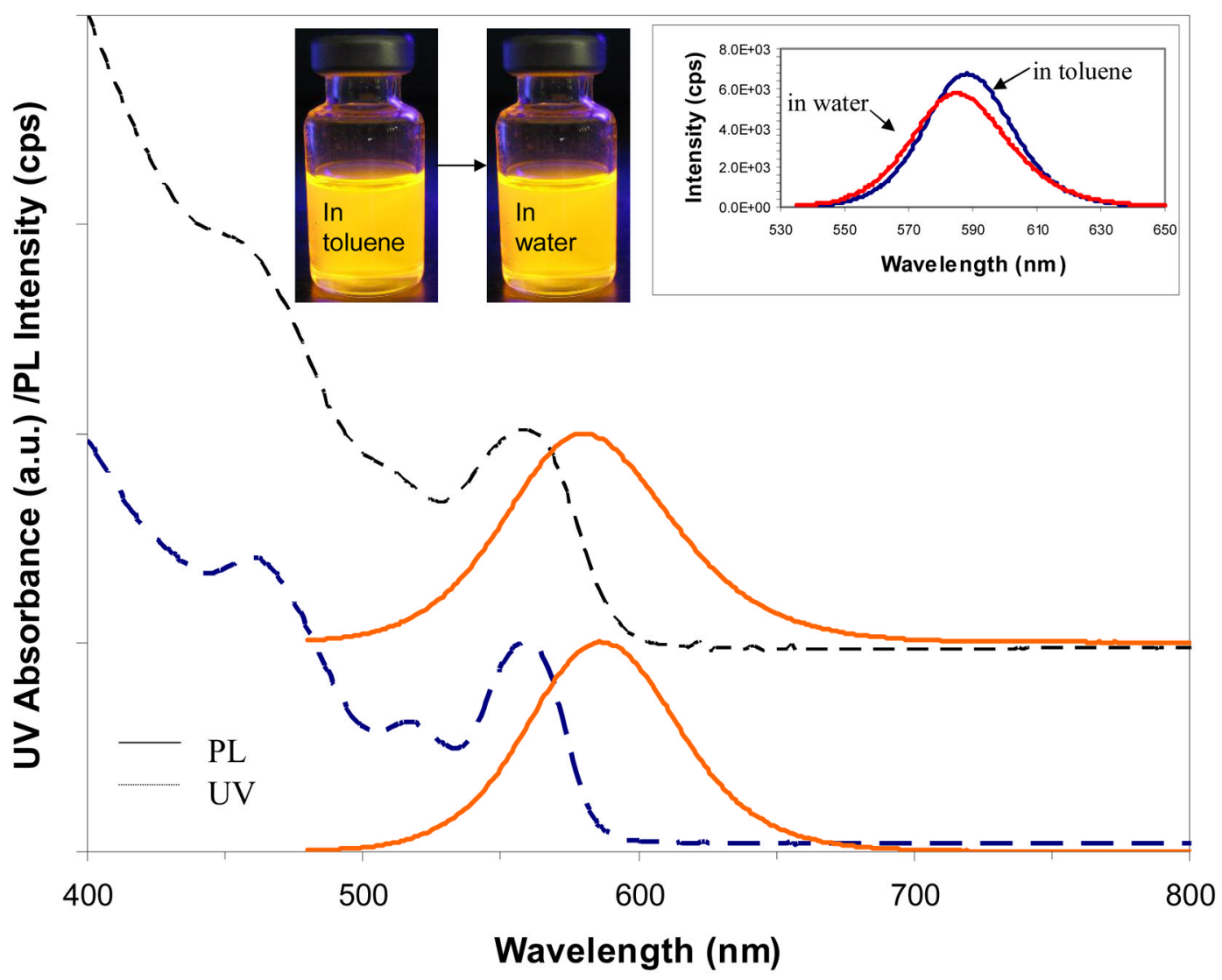

Figure 4.

UV-Vis and PL spectra of the as-synthesized CdSe/ZnS core-shell nanocrystals in toluene and the corresponding dendron-nanocrystals in water. Inset: PL spectra of the nanocrystals before and after dendron ligand modification taken under the same conditions with the same absorbance at the same excitation wavelength. 

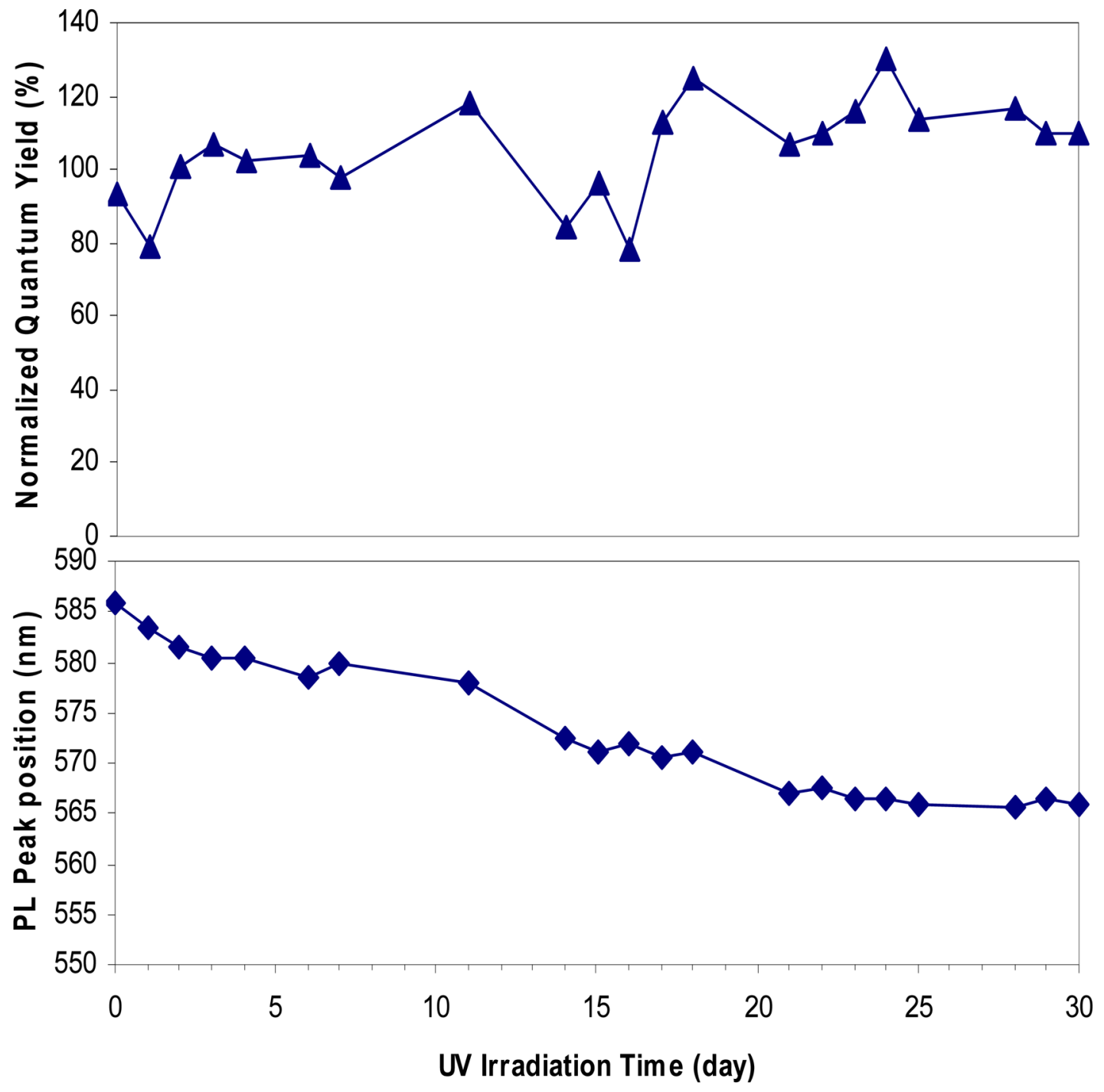

Figure 5.

Effect of UV irradiation in ambient environments on the optical properties of the CdSe/ZnS core-shell dendron-nanocrystal in aqueous solution. 


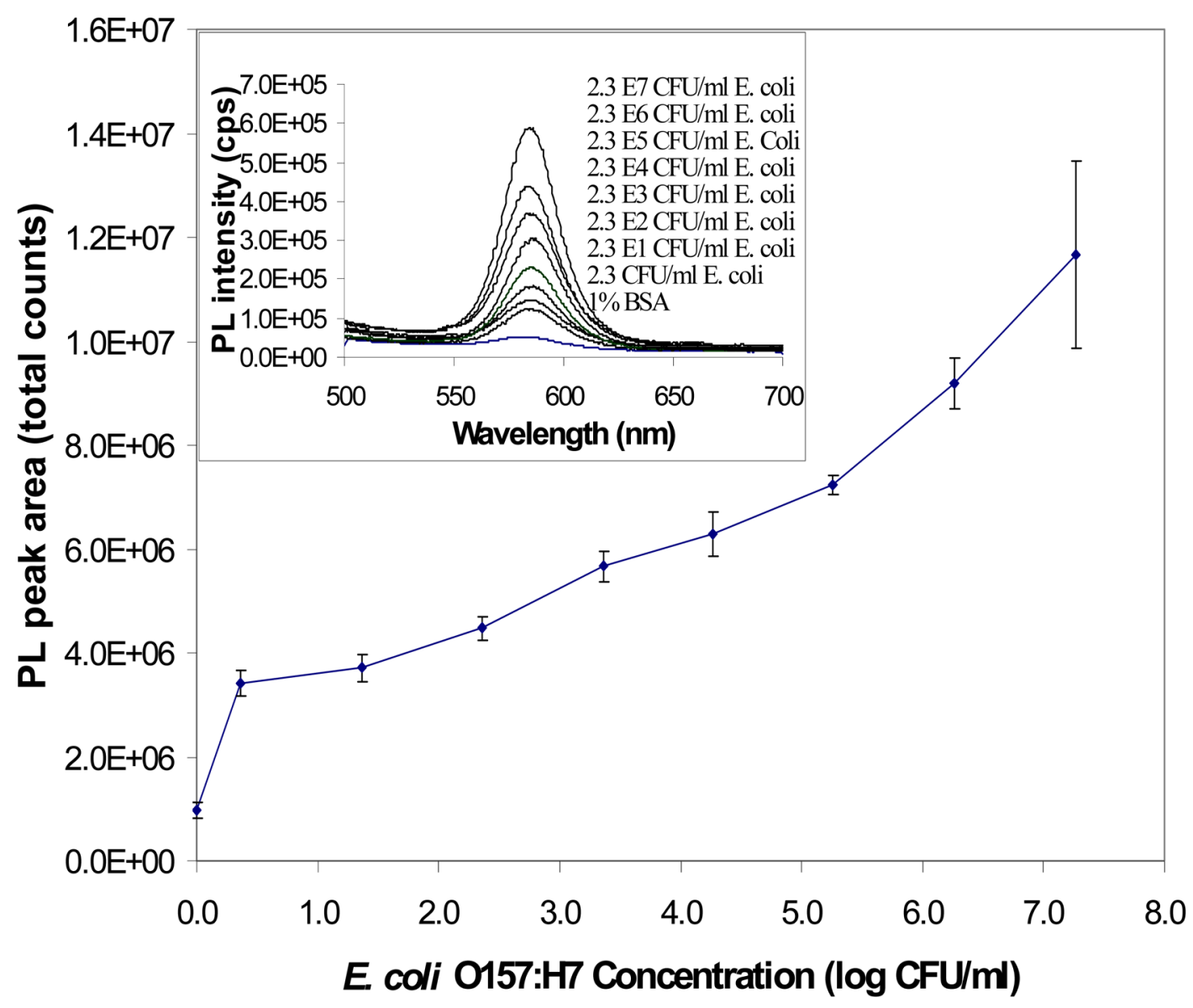

Figure 6.

The curve of the photoluminescence (PL) vs. the concentration of E. coli O157:H7. Inset: PL spectra of the BSA and E. coli O157:H7 samples taken under the same conditions at the same excitation wavelength. 


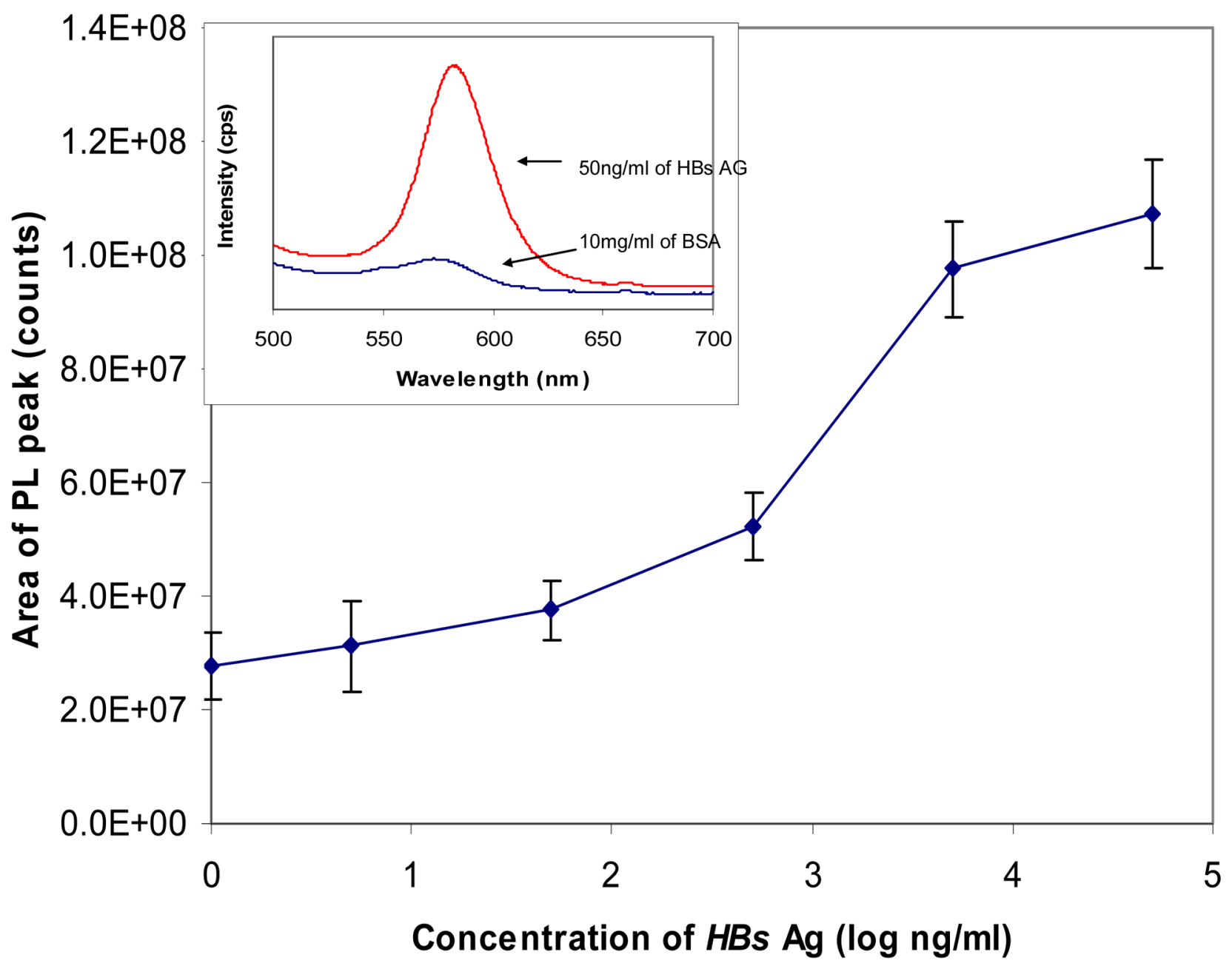

Figure 7.

The curve of the photoluminescence vs. the concentration of HBsAg. Inset: PL spectra of the BSA and HBsAg samples taken under the same conditions at the same excitation wavelength. 